University of Wollongong

Research Online

Faculty of Engineering - Papers (Archive)

Faculty of Engineering and Information

Sciences

$1-1-2012$

\title{
Modelling of temperature-dependent growth kinetics of oxide scale on hot- rolled steel strip
}

Xianglong Yu

University of Wollongong, xly991@uowmail.edu.au

Zhengyi Jiang

University of Wollongong, jiang@uow.edu.au

Dongbin Wei

University of Wollongong, dwei@uow.edu.au

Xiaodong Wang

Shougang University, xiaodong@uow.edu.au

Quan Yang

University of Science and Technology Beijing

Follow this and additional works at: https://ro.uow.edu.au/engpapers

Part of the Engineering Commons

https://ro.uow.edu.au/engpapers/5272

\section{Recommended Citation}

Yu, Xianglong; Jiang, Zhengyi; Wei, Dongbin; Wang, Xiaodong; and Yang, Quan: Modelling of temperaturedependent growth kinetics of oxide scale on hot-rolled steel strip 2012, 219-223.

https://ro.uow.edu.au/engpapers/5272

Research Online is the open access institutional repository for the University of Wollongong. For further information contact the UOW Library: research-pubs@uow.edu.au 


\title{
Modelling of Temperature-Dependent Growth Kinetics of Oxide Scale on Hot-Rolled Steel Strip
}

\author{
Xianglong $\mathrm{Yu}^{1, *}$, Zhengyi Jiang ${ }^{1, *}$, Dongbin Wei ${ }^{1}$, Xiaodong Wang ${ }^{2}$, and Quan Yang ${ }^{3}$ \\ 'School of Mechanical, Materials and Mechatronic Engineering, University of Wollongong, Wollongong NSW 2522, Australia \\ ${ }^{2}$ Shougang Research Institute of Technology, Shougang Group, Beijing, 100043, China \\ ${ }^{3}$ Engineering Research Institute, University Science and Technology Beijing, Beijing 100083, China
}

\begin{abstract}
A numerical simulation, developed to predict the temperature distribution and calculate the growth rate of the oxide scale formed on the microalloyed low carbon steel during the laminar cooling of hot strip rolling, was conducted by two-dimensional finite element method. The model takes into account the different thermophysical properties of the multilayered oxide scales and the film boundary conditions for the water jet impingement zone and the stable film boiling zone through the run-out table. Complied with the parabolic growth of the oxide layers and the distribution of the oxide phase, it is found that the present of wustite (FeO) results in a significant increase of the oxidation rate. However, the parabolic rate constant for the simultaneous growth of the two outer layers of magnetite $\left(\mathrm{Fe}_{3} \mathrm{O}_{4}\right)$ and hematite $\left(\mathrm{Fe}_{2} \mathrm{O}_{3}\right)$ reduce rapidly compared to that of three-layer oxide scale. The growth rates and temperature gradients predicted by the model can be employed to elucidate the formation mechanism of oxide scales, as well as to analyse oxide scale failure.
\end{abstract}

Keywords: Oxide Scale, Hot-Rolled Strip, Growth Kinetics, Rate Constant.

\section{INTRODUCTION}

During hot rolling process, oxide scale grows inevitably on the surface of steel strips. ${ }^{1-2}$ Its properties determine the surface quality ${ }^{3-5}$ and the downstream processability of a hot rolled coil in following process, such as acid pickling, forming or direct coating. ${ }^{6}$ In practice, the final feature of oxide scale in hot strip rolling of low carbon steel depends significantly on the thickness and the phase composition of the tertiary oxide scale, ${ }^{7-9}$ in particular that generated in laminar cooling and coiling processes on a conventional hot strip production line, as shown in Figure 1. Correspondingly, the characteristics of the tertiary oxide scale depend on the finishing temperature (FT) at the exit of the finishing rolling, the amount of cooling applied, and thus on the coiling temperature (CT). ${ }^{10,11}$

Generally, the tertiary oxide scale formed at the exit of the finishing mills, is composed of three well defined layers of iron oxides, namely a thick wustite layer adjacent to the steel substrate, an intermediate magnetite layer, and a thin outermost hematite layer. ${ }^{12,13}$ The same three layer structure is maintained until a eutectoid point of $\mathrm{Fe}-\mathrm{O}$ system, ${ }^{14}$ at $570^{\circ} \mathrm{C}$ is reached. Below $570^{\circ} \mathrm{C}$, the wustite scale layer becomes unstable, and a series of equilibrium transformation occur, pro-eutectoid precipitation of magnetite: 15

$$
(1-4 z) \mathrm{Fe}_{1-x} \mathrm{O} \rightarrow(1-4 x) \mathrm{Fe}_{1-z} \mathrm{O}+(x-z) \mathrm{Fe}_{3} \mathrm{O}_{4}
$$

\footnotetext{
-Authors to whom correspondence should be addressed.
}

where $x>z, \mathrm{Fe}_{1-z} \mathrm{O}$ is an iron-rich wustite, a mixture of $\alpha$-iron and magnetite then occurs:

$$
4 \mathrm{Fe}_{1-2} \mathrm{O} \rightarrow(1-4 z) \mathrm{Fe}+\mathrm{Fe}_{3} \mathrm{O}_{4}
$$

During the formation and transformation of oxide scales, each oxide phase shows its own thermophysical properties" and temperature-dependent growth rates. ${ }^{16-17}$

One of the crucial parameters in the formation of oxide scale is the parabolic rate constant. It can be described by Arrhenius expressions, which is distinct from the Ellingham diagram ${ }^{18}$ modified by Richardson and Jeffes, ${ }^{19}$ even though it conveniently determines the initial oxidation of the various components in the steel from the thermodynamics aspect. The growth kinetics of the oxide scale basically complies with linear, parabolic, paralinear or mixed parabolic law. ${ }^{6}$ Due to the short-time oxidation, less than $100 \mathrm{~s}$, thus the tertiary scale growth in a hot strip mill can be approximately assumed to follow parabolic rate given by:

$$
\Delta x=k_{p} t^{0.5}
$$

where $\Delta x$ is the thickness of oxide scale at a given time $t$, and $k_{p}$ is the parabolic rate constant, which subjects to the type of oxide scale and the formation temperature. The growth rate constant is related to the diffusion of the ionic ions proposed by Wagner, ${ }^{20}$ and $k_{p}$ is also as a function of the deformation temperature, as reported by some authors. ${ }^{16-17} \mathrm{~A}$ series of elegant experiments $\mathrm{s}^{8.13}$ 
have been carried out to study the oxidation kinetics. The weight change of the surface area on specimens before and after the oxidation test in closed furnace can be plotted versus time, and then the rate constant can be determined from the slope. ${ }^{21}$

From a practical standpoint, the growth rate constant frequently replies on time-temperature cycle, laminar cooling scheme, alloy composition and atmosphere conditions. It is necessary to analyse the temperature distribution and to examine the growth kinetics of the hot rolled steel strip during cooling on run-out table. In this paper, an attempt to predict temperature field and corresponding growth rate constant by a heat transfer finite element model has been conducted. The convection and radiation in the surrounding environment and the heat transfer of the film for the water jet impingement zone and the stable film boiling zone during the laminar cooling of hot strip rolling have been taken into account. Of specific interest are the temperature distribution and the kinetics constant of multilayered oxide phase.

\section{THEORETICAL ANALYSIS}

\subsection{Governing Equation}

The heat transfer of the steel strip with oxide scale during the laminar cooling of hot rolling can be shown in Figure $2 .{ }^{22}$ The model takes into account the heat flux through the thickness and the width of the steel strip, and allows for the fine morphological features of the oxide scale, without any pores or cavities within their boundaries.

Then the equilibrium equation of heat transfer is given by

$$
\frac{\partial}{\partial y}\left(\kappa \frac{\partial T}{\partial y}\right)+\frac{\partial}{\partial z}\left(\kappa \frac{\partial T}{\partial z}\right)+\dot{q}=\rho c \frac{\partial T}{\partial t}
$$

where $\dot{q}$ is the heat transfer rate, $\kappa, \rho$ and $c$ are the thermal conductivity, the density and the heat capacity of the material respectively, $T$ is the temperature and $t$ is the time, $y$ and $z$ are the thickness and width coordinate respectively.

Heat losses in the water jet impingement zone during the laminar cooling can be described by

$$
q_{\text {water }}=h_{w 1}\left(T-T_{w 1}\right)
$$

where in Figure $3 h_{w 1}$ is the heat convection coefficient when the jet water contacts the surface of the steel strip, ${ }^{23} T_{w 1}$ is the temperature of the cooling water.

Further heat losses in the stable film boiling zone during the laminar cooling, including the air convection, can be expressed by

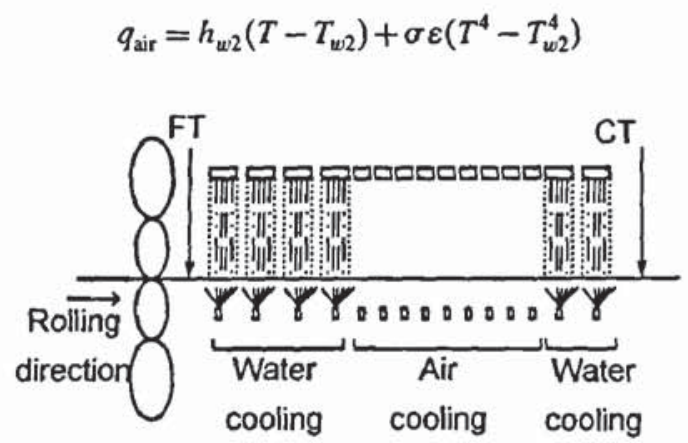

Fig. 1. Illustration of the laminar cooling in a hot strip mill.

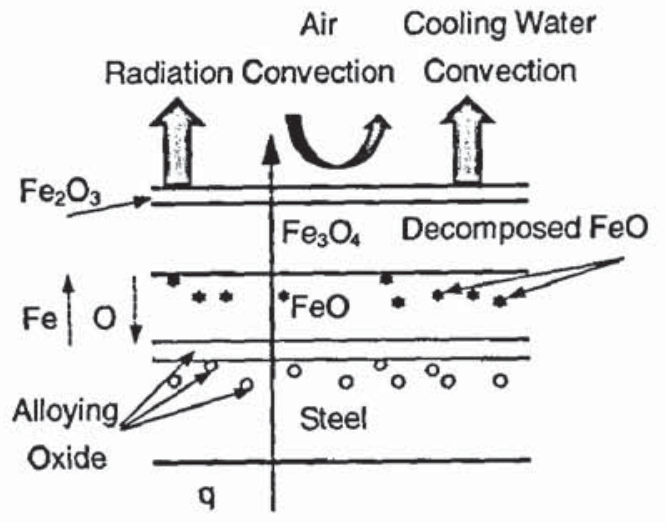

Fig. 2. Heat transfer of three-layer oxide scale.

where $h_{w 2}$ is the film coefficient when the vapor film contacts the surface of the steel strip ${ }^{23}$ (shown in Fig. 3), $T_{w 2}$ is the temperature of the vapor film, $\varepsilon$ is the emissivity of the material and $\sigma=5.6699 \times 10^{-8} \mathrm{~W} /\left(\mathrm{m}^{2} \cdot \mathrm{K}^{4}\right)$ is the Stefan-Boltzmann constant.

The solution for the nodal temperature vector is obtained as the one which minimises the following functional,

$$
\begin{aligned}
I= & \frac{1}{2} \iint_{A}\left[\lambda\left(\frac{\partial T}{\partial x}\right)^{2}+\lambda\left(\frac{\partial T}{\partial y}\right)^{2}-2\left(\dot{q}-\rho c \frac{\partial T}{\partial t}\right) T\right] d A \\
& +\frac{1}{2} \int_{S_{3}} h\left(T-T_{\infty}\right)^{2} d S_{3}
\end{aligned}
$$

Then the resulting governing equation can be written as

$$
\left([K]+\frac{2}{\Delta t}\left[K_{3}\right]\right) \vec{T}_{1}=\left(-[K]+\frac{2}{\Delta t}\left[K_{3}\right]\right) \vec{T}_{0}+\vec{P}
$$

where $[K]$ is the stiffness matrix, $\left[K_{3}\right]$ is the additional under the unsteady state, $\Delta t$ is the interval of time step, $\vec{T}$ the nodal temperature vector and $\vec{P}$ is the equivalent nodal load matrix.

\subsection{Kinetics Models}

Other models, coupled with the growth of the multilayered oxide scales and the distribution of different oxide phases, were established. It was assumed that the growth of oxide scales follows a parabolic law 2,8.10 as shown in Eq. (3). And the oxygen pressure at the steel substrate-oxide scale interface allows for a homogeneous distribution. On the basis of Wagner's theory, ${ }^{20}$ the rate constants can be expressed by the diffusion properties of each phase in terms of the weight of oxygen per unit square area

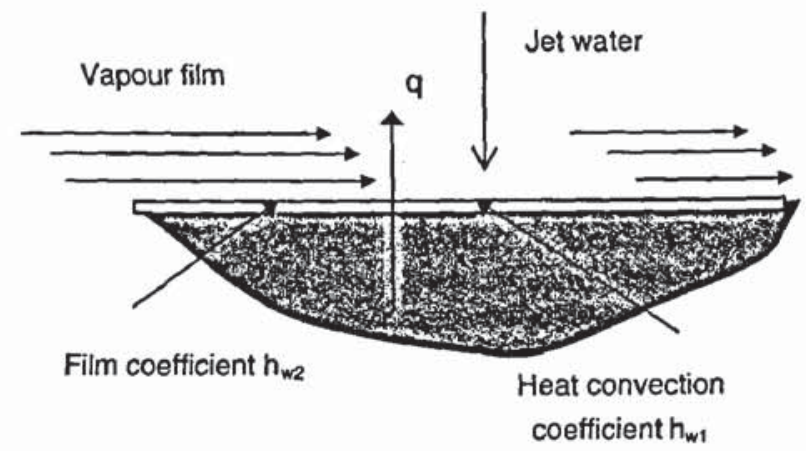

Fig. 3. Film heat convection coefficient of boundary conditions. 
Table 1. Different parabolic rate constants for the modelling.

\begin{tabular}{lccc}
\hline Item & $k_{1} / \mathrm{g}^{2} \mathrm{~cm}^{-4} \mathrm{~s}^{-1}$ & $k_{2} / \mathrm{g}^{2} \mathrm{~cm}^{-4} \mathrm{~s}^{-1}$ & $k_{3} / \mathrm{g}^{2} \mathrm{~cm}^{-4} \mathrm{~s}^{-1}$ \\
\hline $\mathrm{FeO}$ & 12.47 & & {$\left[k_{1}^{(\mathrm{FeO})}+k_{1}^{\left(\mathrm{F} \theta_{3} \mathrm{O}_{4}\right)}\right.$} \\
& $\exp \left(-172.4 \times 10^{3} / R T\right)$ & & $\left.+k_{1}^{\left(\mathrm{Fe}_{2} \mathrm{O}_{3}\right)}\right]^{2}$ \\
$\mathrm{Fe}_{3} \mathrm{O}_{4}$ & $1.98 \times 10^{-2}$ & {$\left[k_{1}^{\left(\mathrm{Fe}_{3} \mathrm{O}_{4}\right)}+k_{1}^{\left(\mathrm{Fe}_{2} \mathrm{O}_{3}\right)}\right]^{2}$} & \\
& $\exp \left(-169.5 \times 10^{3} / R T\right)$ & \\
$\mathrm{Fe}_{2} \mathrm{O}_{3}$ & $1.49 \times 10^{-3}$ & \\
& $\exp \left(-169.5 \times 10^{3} / R T\right)$ & \\
\hline
\end{tabular}

Note: "Temperature is expressed in $\mathrm{K}, R=8.31441 \pm 0.00026 \mathrm{~J} / \mathrm{mol}-\mathrm{K}$

$\left(\mathrm{g}^{2} \mathrm{~cm}^{-4} \mathrm{~s}^{-1}\right)$. Thus, the parabolic rate constants of the first kind for the growth of $\mathrm{FeO}, \mathrm{Fe}_{3} \mathrm{O}_{4}$ and $\mathrm{Fe}_{2} \mathrm{O}_{3}$ in the air oxidation between 700 and $1000{ }^{\circ} \mathrm{C}$ can be determined in Table $\mathrm{I}^{16,17}$ Therefore, the rate constant of multilayer oxide scale can be calculated from the first kind of these compounds.

\section{SIMULATION}

\subsection{FE Mesh}

Heat transfer within the multilayered oxide scale and the steel strip is simulated by two-dimensional finite element method ${ }^{25}$ using ABAQUS/Standard software. The simulation model is shown in Figure 4. The oxide scale is $50 \mu \mathrm{m}$ thick divided into 9461 nodes or 4524 elements of DC2D6, in which wustite is considered to be $45 \mu \mathrm{m}$, magnetite is $4.5 \mu \mathrm{m}$ and hematite is $0.45 \mu \mathrm{m}$, according to the reported proportions. ${ }^{8,12}$ The steel substrate is meshed to 1174 nodes or 2209 elements, based on assumed symmetrical cooling on the top and bottom surface.

\subsection{Simulation Conditions}

Thermal properties of the oxide scale are listed in Table II. The finishing temperature and coiling temperature are 860 and $560^{\circ} \mathrm{C}$ respectively. The properties of the steel strip were considered to be temperature dependent. ${ }^{10}$

The heat convection coefficient $h_{w 1}$ can be calculated by ${ }^{23}$

$$
h_{w 1}=P_{r}^{0.33}\left(0.037 R e^{0.8}-850\right) \frac{\lambda}{W}
$$

where $P_{r}$ is the Planck constant, $P_{r}=\mu_{f} c_{p} / \lambda_{w}, \mu_{f}$ is the dynamic viscosity, $c_{p}$ is the specific heat at a constant pressure, $\lambda_{w}$ is the thermal conductivity, $R e$ is the Reynolds number, $R e=w \rho_{c} v / \mu_{f}, w$ is the width of the impingement zone, $v$ is the jet velocity.

The film coefficient $h_{w 2}$ can be calculated by ${ }^{23}$

$$
h_{w 2}=\lambda_{s}\left(\frac{g \Delta \rho}{8 \pi \lambda_{s} \alpha_{c}}\right)^{1 / 3} \quad \alpha_{c}=\frac{\lambda_{s} \theta_{s}}{2 i_{f b} \rho_{s}}
$$

where $\Delta \rho$ is the difference of the density, $\theta$ is the different of the temperature, $i$ is specific enthalpy, the subscript $s$ and $f b$

Table II. Thermal properties of oxide scale.

\begin{tabular}{lcrrr}
\hline Item & Austenite & $\mathrm{FeO}$ & $\mathrm{Fe}_{3} \mathrm{O}_{4}$ & $\mathrm{Fe}_{2} \mathrm{O}_{3}$ \\
\hline$K \mathrm{~W} / \mathrm{m} \cdot \mathrm{K})$ & $16.5 \pm 0.11 T$ & 3.2 & 1.5 & 2 \\
$\rho\left(\mathrm{kg} / \mathrm{m}^{3}\right)$ & $8050-0.5 T$ & 725 & 870 & 980 \\
$C_{p}(\mathrm{~J} / \mathrm{kg} \cdot \mathrm{K})$ & $587.8 \pm 0.068 T$ & 7750 & 5000 & 4900 \\
\hline
\end{tabular}

Note: "Temperature is expressed in ${ }^{\circ} \mathrm{C}$.

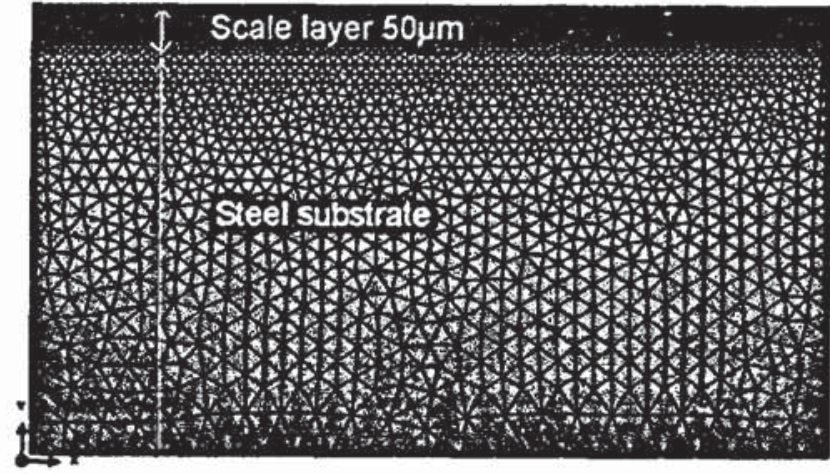

Fig. 4. Finite element mesh for oxide scale and steel substrate.

are the saturated vapor and the steady film boiling respectively. In this study, the relationship between the film coefficient and temperature, shown in Figure 5, has been applied, which can be load by the FILM code in ABAQUS software.

In addition, the emissivity of the surface strip $\varepsilon$ can be directly determined by ${ }^{24}$

$$
\varepsilon=1.1+\frac{T-273}{1000}\left(0.125 \frac{T-273}{1000}-0.38\right)
$$

\section{RESULTS AND DISCUSSION}

\subsection{Distribution of Temperature}

Figure 6 shows the distribution of the temperature along the thickness direction of the hot-rolled steel strip, in which the individual temperature of the oxide scale and the steel substrate are marked. Sharp gradient exists in the thickness range of the oxide scale, as a result of the low thermal conductivity of the oxide scale. ${ }^{10.11}$ The abrupt change of temperature possibly leads to the generation of some thermal stress at the interface of the oxide layer and the substrate, and further affects the integrity of oxide scales.

\subsection{Parabolic Rate Constant}

The overall parabolic rate constant for the simultaneous growth of the three layers, $k_{3}$, is shown in Figure 7. In the range of 800

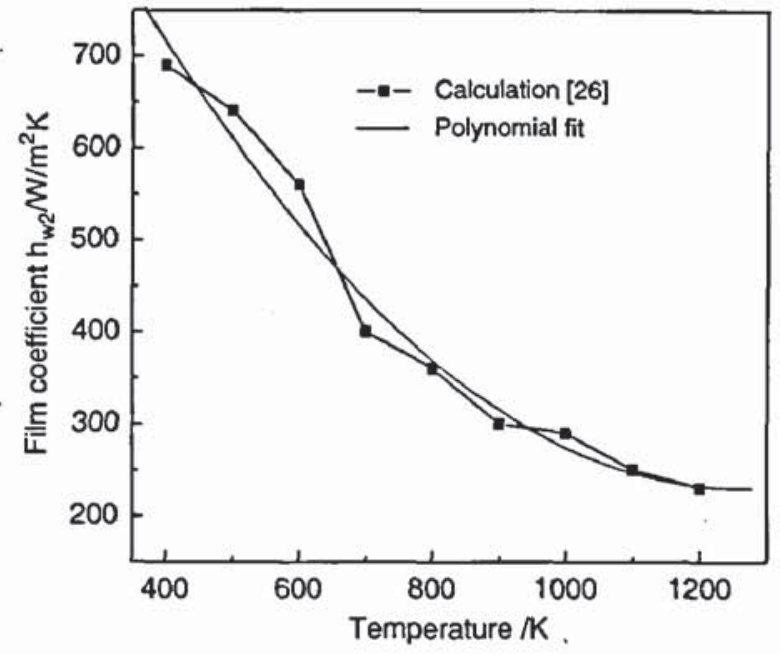

Fig. 5. Film coefficient of heat convection against temperature. 


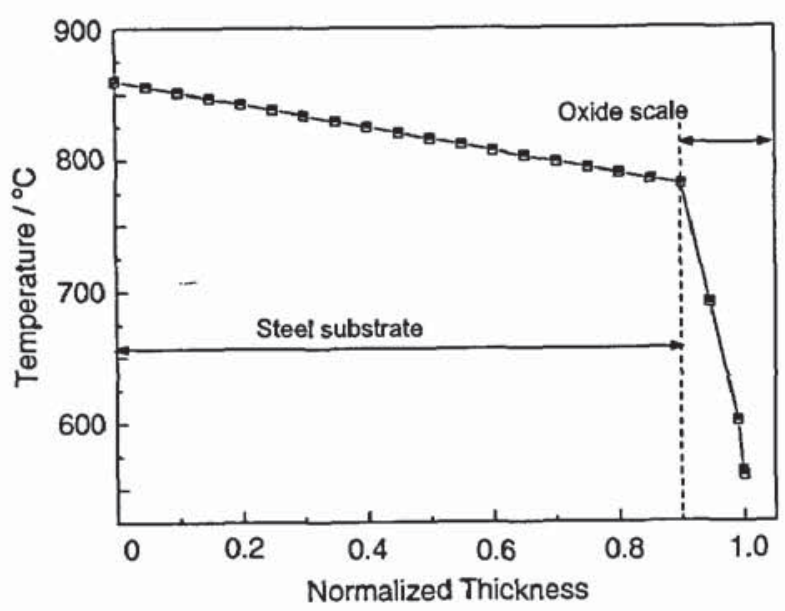

Fig. 6. Temperature distribution along thickness of steel strip.

to $850^{\circ} \mathrm{C}$, the growth rate constant rapidly increases. However, a relatively gentle increase occurs in the range of 700 to $800{ }^{\circ} \mathrm{C}$.

The second rate constant for the growth of the two outer layers of $\mathrm{Fe}_{3} \mathrm{O}_{4}$ and $\mathrm{Fe}_{2} \mathrm{O}_{3} k_{2}$, is shown in Figure 8. The oxygen pressure prevailing at the $\mathrm{Fe}-\mathrm{Fe}_{3} \mathrm{O}_{4}$ interface is assumed to correspond to that for the $\mathrm{FeO}-\mathrm{Fe}_{3} \mathrm{O}_{4}$ equilibrium. It can be seen that the second rate constant, $k_{2}$, and $k_{3}$ are in the order of magnitude, $10^{-10}$ and $10^{-8}$ respectively. The diffusion coefficient of ions contributes to a higher oxidation rate in $\mathrm{FeO}$ layer than in $\mathrm{Fe}_{3} \mathrm{O}_{4}$ and $\mathrm{Fe}_{2} \mathrm{O}_{3}$ layers. In practice, the oxygen pressure at the substrate-oxide scale interface may differ from that assumed in these models.

The results show that the main reason for the decrease in the oxidation rate in the hot rolled steel strip during the laminar cooling with respect to before the finishing rolling is the disappearance of $\mathrm{FeO}$ phase in the oxide scales. It is in good agreement with the establishment of the steepest thermal gradients within the oxide scale that can lead to the highest growth rate. ${ }^{10}$ In addition, the selective oxidation and the internal oxidation ${ }^{16}$ of microalloy low carbon steel can cause rate constant somewhat different from this study. Therefore, the final thickness of the oxide scale can be calculated using the growth rate constant in

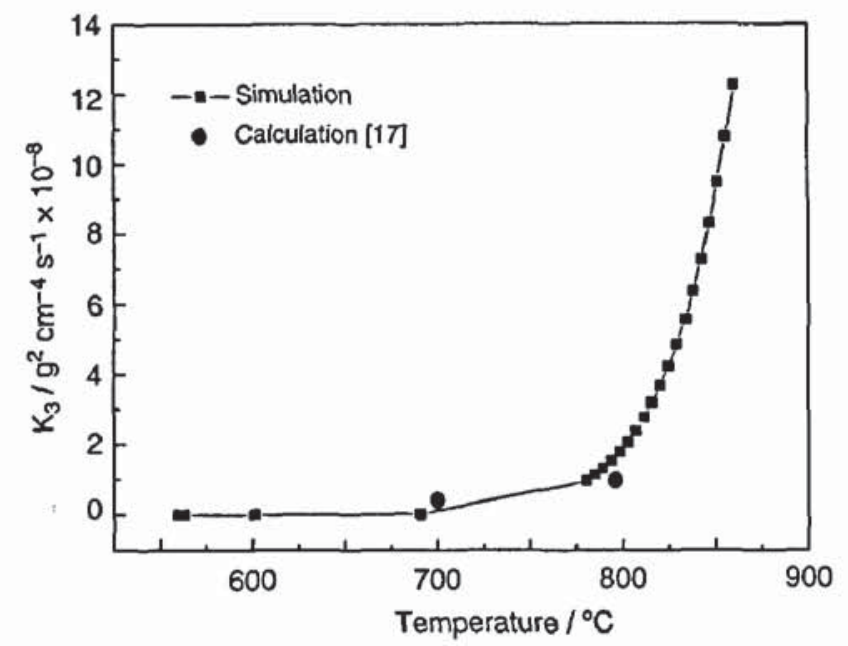

Fig. 7. Rate constant of three-layer oxide scale against temperature distribution.

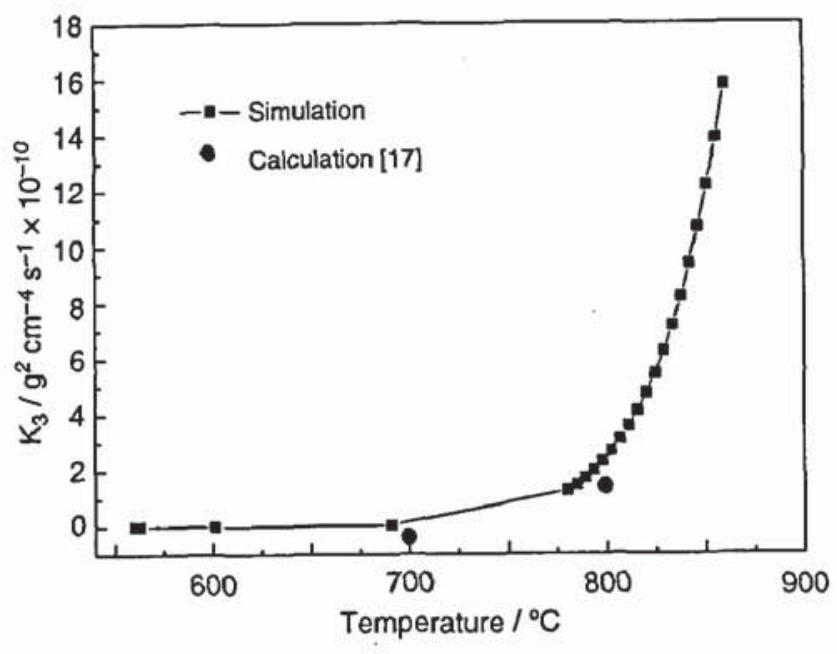

Fig. 8. Rate constant for oxide layer of magnetite and hematite against temperature distribution.

the individual oxide layer, and analysis on the evolution of the individual oxide phase can be calculated.

\section{CONCLUSIONS}

A numerical model, considering the film boundary conditions during laminar cooling and growth kinetics of the oxide scale, has been established to obtain the temperature distribution within the oxide layers formed on the hot-rolled steel strip and the corresponding parabolic rate constant. The present of wustite ( $\mathrm{FeO}$ ) phase results in a significant increase of the oxidation rate, and the steeper thermal gradients within the oxide scale can increase the growth rate. However, the growth rate constant for the simultaneous growth of the two outer layers of magnetite $\left(\mathrm{Fe}_{3} \mathrm{O}_{4}\right)$ and hematite $\left(\mathrm{Fe}_{2} \mathrm{O}_{3}\right)$ has a significant decrease with respect to that of three-layer oxide scale. The present model can be applied to obtain more information including the phase transformation of wustite at $570{ }^{\circ} \mathrm{C}$ within the oxide scale, which can then be employed to explore the formation mechanism, and further to adjust the phase composition of the oxide scale formed on hot-rolled steel strip.

Acknowledgments: This work was supported by the China Scholarship Council (CSC)-University of Wollongong (UOW) Research Program for Ph.D study.

\section{References and Notes}

1. W. L. Roberts, Hot Rolling of Steel, Marcel Dekker, Inc., New York (1983).

2. M. Krzyzanowski, J. H. Beynon, and D. C. J. Farrugia, Oxide Scale Behavior in High Temperature Metal Processing. Wiley-VCH, Darmstadt (2010).

3. Z. Y. Jiang. A. K. Tieu, W. H. Sun, J. N. Tang, and D. B. Wei, Mat. Scl. Eng. A-Struct. 435-436, 434 (2006).

4. D. B. Wei, J. X. Huang, A. W. Zhang, Z. Y. Jiang, A. K. Tieu, X. Shi, S. H. Jiao, and X. Y. Qu, Wear 267, 1741 (2009).

5. Z. Y. Jiang, J. Tang, W. Sun, A. K. Tieu, and D. Wei, Tribol. Int. 43, 1339 (2010).

6. P. H. Bolt, Steel Res. Int. 75, 399 (2004).

7. W. H. Sun, A. K. Tieu, Z. Y. Jiang. J. N. Tang, and D. B. Wei, J. Mater. Process. Technol. 155-156, 1300 (2004).

8. R. Y. Chen and W. Y. D. Yuen, Oxid. Met. 59, 433 (2003).

9. D. B. Wei, J. X. Huang, A. W. Zhang. Z. Y. Jiang, A. K. Tieu, F. Wu, X. Shi, and S. Jiao, Int. J. Surf. Sci. Eng. 3, 459 (2009).

10. M. Torres and R. Colas, J. Mater. Process. Technol. 105, 208 (2000). 
11. M. Krzyzanowski and J. H. Beynon, Metal Forming Science and Practice, edited by J. G. Lenard, Elsevier, Sydney (2002), Chap. 13, pp. 270-271.

12. J. Paidassi, Acta Metall. 6, 184 (1958).

13. R. Y. Chen and W. Y. D. Yuen, Oxid. Met. 53,539 (2000).

14. H. A. Wriedt, Binary Alloy Phase Diagrams, edited by T. B. Massalski, H. Okamoto, P. R. Subramanian, and L. Kacprzak, ASM Intern., Materials Park (1990), Vol. 2, pp. 1739.

15. B. Gleeson, S. M. Hadavi, and D. J. Young, Mater. High. Temp. 17, 11 (2000)

16. F. Gesmundo, Y. Niu, D. Oquab, C. Roos, B. Pieraggi, and F. Viani, Oxid. Mot. 49, 115 (1998)

17. F. Viani and F. Gesmundo, Corrosion Sci. 20,541 (1980).
18. J. T. H. Ellingham, J. Soc. Chem. Ind.-L. 63, 125 (1944).

19. F. D. Richardson and H. Jeffes, ISIJ 160, 261 (1948).

20. C. Wagner, Atom Movements, Am. Soc. Met. Metals Park (1951).

21. C. A. C. Sequeira, Uhlig's Corrosion Handbook, edited by R. W. Revie, John Wiley \& Sons, Inc., New Jersey (2011), Chap. 20, pp. 247-280.

22. D. A. Zumbrunnen and M. Aziz, J. Heat Trans. -T. ASME 115, 91 (1993).

23. K. Jun-ichi, H. Natsuo, T. Hirohiko, Y. Nobuo, and H. Jun, Archiv. Eisenhuettenw. 55, 113 (1984).

24. P. R. Chappidi, F. S.Gunnerson, and K. O. Pasamehmetoglu, Int. Commun. Heat Mass 17, 259 (1990).

25. Q. Liu, W. Fu, C. Lu, K. Tieu, and M. Li, Adv. Sci. Lett. 4, 2054 (2011).

Received: 28 July 2011. Accepted: 25 October 2011. 